\title{
As mulheres à beira de um império nervoso na obra de Paulina Chiziane e Ungulani Ba ka Khosa ${ }^{1}$
}

\author{
Hilary Owen
}

Machester University

RESUMO: ESTE ARTIGO FAZ UMA LEITURA COMPARATIVA DO CONCEITO DE "FRONTEIRA NACIONAL" EM UALALAPI, DE UNGULANI BA KA KHOSA, E AS ANDORINHAS, DE PAULINA CHIZIANE, OBRAS ONDE FIGURA O IMPERADOR DE GAZA, NGUNGUNHANE. EM KHOSA, ABORDAREI A INFLUÊNCIA DO CONCEITO DE "ABJECÇÃO" (EXPULSÃO DO CORPO MATERNAL ABJECTO) NA DEFINIÇÃO DESSA FRONTEIRA SEGUNDO O MODELO IMPERIAL E EXPANSIONISTA DE NGUNGUNHANE, ENTÃO COOPTADO PELA FRELIMO (CHANGAANIZADA) DE MACHEL. COM CHIZIANE, APRESENTO UMA OUTRA VISÃO DO TERMO, BASEADA NAS MITOLOGIAS CHOPES EM TORNO DO FUNDADOR DA FRELIMO EDUARDO MONDLANE E DA ATLETA LURDES MUTOLA.

ABSTRACT: THIS ARTICLE PROVIDES A COMPARATIVE READING OF THE "NATIONAL FRONTIER" CONCEPT, ACCORDING TO UALALAPI, BY UNGULANI BA KA KHOSA, AND AS ANDORINHAS, BY PAULINA CHIZIANE - WORKS THAT REPRESENT THE GAZA EMPEROR NGUNGUNHANE. WITH KHOSA, I SHOW THE INFLUENCE THAT THE CONCEPT OF "ABJECTION" (THE EXPULSION OF THE ABJECT MATERNAL BODY) IN DEFINING THE NATION'S FRONTIERS, AS THE IMPERIAL, EXPANSIONIST MODEL, BY NGUNGUNHANE, ALSO EMBRACED BY MACHEL'S CHANGAANIZED FRELIMO. AS FOR CHIZIANE, I PRESENT ANOTHER VISION OF THE CONCEPT, BASED ON THE CHOPE MYTHOLOGIES SURROUNDING FRELIMO FOUNDER EDUARDO MONDLANE, AND THE ATHLETE LURDES MUTOLA.

PALAVRAS-CHAVE: NAÇÃO, CORPO, MOÇAMBIQUE, UNGULANI BA KA KHOSA, PAULINA CHIZIANE.

KEYWORDS: NATION, BODY, MOZAMBIQUE, UNGULANI BA KA KHOSA, PAULINA CHIZIANE.

1. Expresso meu sincero agradecimento a Sara Ramos Pinto pela tradução deste artigo do Inglês para o Português. 
romance Ualalapi (1987) de Ungulani Ba Ka Khosa organiza-se, de forma já sobejamente conhecida, em torno de Ngungunhane, o Imperador de Gaza, do século XIX, derrotado e capturado pelos portugueses durante a campanha conhecida como a "Pacificação de Gaza", que fez do General português Mouzinho de Albuquerque um herói colonial. Na sua abordagem pós-moderna da historiografia portuguesa dominante do Império, Ualalapi já há muito que se estabeleceu como um clássico da literatura moçambicana na medida em que, além de tudo o mais, oferece uma crítica paralela, ainda que velada, das tendências imperialistas e totalitárias do primeiro presidente moçambicano da era pós-independência, Samora Machel. Tal como foi já largamente discutido por autores diversos, o conceito de nacionalidade de Samora Machel aproveitou em certa medida as mitologias associadas a Ngungunhane não só como o herói da resistência Nguni, mas também como unificador, por subjugação, dos grupos étnicos vizinhos do Sul, e especificamente, os chopes ${ }^{2}$.

O exemplo mais eloquente do uso que Samora Machel fez da mitologia de Ngungunhane diz respeito à sua decisão em 1985 de celebrar os 10 anos da independência de Moçambique com a trasladação dos restos mortais de Ngungunhane - que haviam sido enterrados nos Açores (local onde os portugueses o mantiveram em exílio) - para Moçambique, onde foram celebrados. Neste sentido, a narrativa sulista e predominantemente changane de Samora Machel sobre a nação conseguiu uma das suas mais concretas validações míticas. $\mathrm{O}$ romance de Khosa resiste claramente a esta tradição heróica, uma vez que desvela as ambivalências multifacetadas da história de Ngungunhane, fazendo com que este surja como o anti-herói tirânico aos olhos de quem ele subjugou e, simultaneamente, como a nobre vítima alvo da traição dos portugueses. Tal como Jared Banks teve oportunidade de expor, a aceitação de Ngungunhane:

as a national figure has not been unanimous. Increasingly Mozambicans from other parts of the country, or those whose ancestors were subjugated by

\footnotetext{
2. Tal como Jared Banks teve oportunidade de discutir, o regime de Samora Machel via Ngungunhana "as the Great predecessor of national unity [whose] heroicization culminated in 1985; as part of the tenth anniversary of independence, the 'restos mortais' [...] of Ngungunhana were returned to Mozambique and lavished with political and cerimonial praise" (BANKS, 2010,p. 174). Em Michel Cahen e Severino Ngoenha é igualmente discutida a presença de Ngungunhana e o Império de Gaza no discurso de fundação nacional da FRELIMO (CAHEN, 1999; NGOENHA, 1999).
} 
Ngungunhana, have come out against his employment as a 'hero'. (BANKS, 2010:174)

De tal modo, a obra-prima de Khosa percorre um longo caminho no sentido da descentralização das assumpções monolíticas - em níveis cultural, étnico e político - sobre as quais Samora Machel construiu a visão de uma nação heróica unida e notoriamente changanizada.

A colectânea de contos de Paulina Chiziane, As andorinhas, publicada em Maputo em 2008, revisita igualmente o tema de Ngungunhana e do Império de $\mathrm{Gaza}^{3}$. O seu trabalho surge, no entanto, no contexto das comemorações mais recentes em torno do aniversário dos 40 anos da morte do fundador e primeiro líder da FRELIMO, Eduardo Mondlane ${ }^{4}$. Morto por um pacotebomba em Dar-es-Salaam, em 1968, Mondlane foi sucedido como líder da FRELIMO por Samora Machel, que efectivamente manteve unido o movimento de luta armada de libertação durante um período de radicalização comunista e, após o fim da guerra colonial em 1974, procurou unificar a nação recém-independente sob um regime republicano marxista-leninista. A decisão de Chiziane de sobrepor a história de Eduardo Mondlane com a de Ngungunhane é em si mesmo testemunho do questionar do legado de Ngungunhane, precisamente por aqueles cujos antepassados haviam sido, conforme exposto por Banks, acima, subjugados por Ngungunhane. Tanto Eduardo Mondlane quanto a própria Paulina Chiziane pertencem ao grupo étnico chope, que em tempos foi oprimido pelos guerreiros de Ngungunhane.

Posto isto, enquanto o primeiro conto de Chiziane, "Quem manda aqui?" diz directamente respeito à história de Ngungunhane e a como ele veio a ser derrotado pelos portugueses, este é seguido pelo conto, "Maundlane, o Criador", onde são reconstruídas as origens míticas e heróicas de Eduardo Mondlane.

3. Gostaria de agradecer muito a Maria Armanda Fortes Tavares pelas produtivas conversas sobre $A s$ Andorinhas no contexto do seu próprio trabalho sobre as heroínas políticas moçambicanas. Recomendo a consulta do seu artigo "Karingana Wa Karingana: Representations of the Heroic Female in Mozambique" (apresentado na conferência "Gender, Empire and Postcolony: Intersections in Luso-AfroBrazilian Studies na UMass, Dartmouth, 9-11 de Outubro de 2009) sobre a construção de género e a nação relativamente a Maria de Lurdes Mutola e Josina Machel.

4. A ortografia de Ngungunhane varia de acordo com a transcrição utilizada. Opto aqui por seguir a ortografia de Khosa do nome como Ngungunhane quando se refere a Ualalapi, e a ortografia de Chiziane como Ngungunhana quando se refere a As Andorinhas. 
A colectânea termina com, "Mutola, a Ungida", um tributo à atleta olímpica moçambicana, Maria de Lurdes Mutola, vencedora de uma medalha de ouro.

O principal objectivo neste artigo é comparar a forma como estas duas obras, de Khosa e Chiziane, apresentam um olhar crítico sobre o legado de Ngungunhane de forma a desafiar os limites da ideologia nacional institucional. No romance de Khosa, a representação de Ngungunhane serve, pelo menos num primeiro nível, para desestabilizar a masculinidade hegemónica da nação como império, seja este nguni ou português, assim como para desconstruir a dominação exercida por esta masculinidade nacional sobre a narração da história. Para Chiziane, que dá mais peso à desterritorialização das mitologias sexuadas da nação, a utilização da história de Ngungunhane permite a re-conceptualização da própria diferença sexual pela e como nação. Neste processo, a dissidência narrativa de ambos os escritores põe em causa a ideologia nacional de Samora Machel, autorizada pelo modelo patriarcal do heróico Império de Gaza.

A tudo isso Chiziane acresce ainda o importante paradigma alternativo da heróica linhagem dos chopes, assim como a influência social feminina incorporada na história familiar de Eduardo Mondlane. Central para a estética da narrativa de ambos os textos é o papel metafórico assumido pelo corpo sexuado como forma de mapeamento da nação. A figura da Mãe, como símbolo do território nativo, é, naturalmente, um já bem vincado lugar-comum do discurso nacionalista e da literatura de luta independentista. O que me proponho discutir neste artigo é que esta tropologia monolítica sexual da "Mãe Boa" da nacionalidade pode ser desconstruída para revelar diferentes estruturas de ideologia e identificação sexual, conforme a nação seja configurada pelas fronteiras em contínua expansão, próprias do estado imperial narcísico (como no caso das conquistas de Ngungunhane) ou pelas estratégias protectoras e integracionistas que emergem da nova versão da história de Eduardo Mondlane por Chiziane.

Em Ualalapi, de Khosa, a mais famosa e impressionante imagem de uma mulher é a de Damboia, uma mulher não-mãe, que surge no terceiro episódio do romance, sob a forma da monstruosa e envelhecida amante do imperador. Damboia não tem filhos e as passagens que Khosa a ela dedica especificamente narram as circunstâncias da sua morte, devido a uma menstruação de três meses, fazendo lembrar a hemorragia própria da menopausa. Ao narrador de Khosa, que transcreve as histórias orais que lhe são contadas em volta 
da fogueira, são-lhe, significantemente, dadas duas versões alternativas desta história. Na primeira, contada por um dos guardas de Damboia, Mulele, o ritual sagrado anual de nkuia, cujo objectivo é fortalecer o império, é desacostumadamente cancelado pelo imperador em sinal de respeito pelo estado de Damboia. Com este gesto, Ngungunhane reforça a mensagem de que o corpo doente de Damboia personifica o império, de tal modo que "se ela se vai, vai-se o império, homens!” (KHOSA, 1990:63). À medida que a sua doença progride, acontecem chuvas terríveis e cadáveres do passado, sem nome ou face, são trazidos com a subida das águas. Uma vez falecida Damboia, cinco dos homens mais viris tornam-se impotentes.

A segunda versão é contada por Ciliane, uma serva de Damboia, e apresenta desfasamentos e fissuras face à primeira. Ciliane afirma que Damboia jamais fora tão feliz como nos seus últimos momentos; contudo, os vassalos do império viam a sua doença como punição pelo seu conhecido comportamento devasso, na medida em que tinha a reputação de ter mandado matar jovens guerreiros quando estes não satisfaziam os seus desejos sexuais. Em resposta às questões de Ciliane, relativamente à sua moralidade, Damboia terá confirmado que os homens tinham sido executados por não aceitarem dormir com ela, e que à hora da morte a teriam amaldiçoado a suportar uma morte horrenda.

A sua morte é de facto uma dupla morte, já prefigurada na sua infertilidade. À medida que a hemorragia se agrava e sobe à altura dos tornozelos, a areia já não consegue absorvê-la e o fluxo parte as bilhas em que as pessoas tentam contê-lo. A dado momento Damboia cede à insanidade e ao comportamento animalesco - segundo as palavras de Ciliane, "a loucura invadiu-a. Começou a andar de gatas, e a trepar as paredes da casa, como um réptil em desespero. Durante a noite, uivava como os cães" (KHOSA, 1990:70). Os homens que a guardavam sucumbem à surdez ou à insanidade. À medida que o seu sangue escoa para os rios, este acaba por matar os peixes, poluir as águas e atrair crocodilos para terra em número crescente. Por fim, à hora da morte de Damboia há uma tempestade e diversos cadáveres de nados-mortos nascem nas marés das chuvas torrenciais. O imperador Ngungunhane tinha, entretanto, viajado pelo território a difundir notícias positivas, de que tudo estava bem, de forma a tentar conter os relatos orais contrários, provenientes da boca de servas como Celiane, que se espalhavam como fogo. 
Não será difícil ver aqui, em termos míticos, o reverso horripilante da Mãe Boa, da figura reprodutora e regenerativa da iconografia nacionalista, na medida em que Khosa faz com que os excessos inférteis e improdutivos de Damboia e Ngungunhane assumam a conotação da fatalidade da nação imperial. De forma semelhante, Paulina Chiziane escreveu sobre o papel da mulher nas mitologias Bantu e, mais especificamente, Tsonga do Sul de Moçambique, que são transformadas em bodes expiatórios de desastres naturais; assim:

[q]uando uma grande desgraça recai na comunidade sob a forma de seca, epidemias, guerra, as mulheres são severamente punidas e consideradas as maiores infractoras dos princípios religiosos da tribo [... ] é o sangue podre das suas menstruações, dos seus abortos, dos seus nado-mortos que infertiliza a terra, polui os rios, afasta as nuvens e causa epidemias, atrai inimigos e todas as catástrofes. (CHIZIANE, 1994:12)

Aproveitando a teoria psicanalítica, é fácil identificar aqui uma correspondência íntima com o conceito do "abjecto", cunhado por Julia Kristeva. No pensar de Kristeva, "o abjecto" serve para descrever o modelo de formação do sujeito social, que não é dependente de uma simples oposição sujeito/ objecto, mas, ao contrário, permite também a consideração do espaço-entre (between-space) do "abjecto". "O abjecto" refere-se à expulsão nunca completa da matéria indesejada (a exemplo da sujidade, do sangue menstrual, do vómito, do sémen ou do excremento) através das fronteiras do Eu; de tal forma que tal matéria permanece sempre ainda contida no $\mathrm{Eu}$, como se se tratasse de um "limite interior", que pressiona para voltar, de dentro das margens.

Para Kristeva, a abjecção pode, deste modo, conotar uma espécie de "narcissistic crisis" (KRISTEVA, 1982:14) particular. Em termos religiosos e antropológicos, o abjecto pode descrever os domínios colectivo e social de exclusão ou o tabu; enquanto em termos sociais, serve para definir o "inbetween, the ambiguous, the composite. The traitor, the liar, the criminal with a good conscience" (KRISTEVA, 1982:4). No contexto pós-colonial, Anne McClintock argumentou, igualmente, a favor da consideração do paradoxo da abjecção "as a formative aspect of modern, industrial [British] colonialism" (McCLINTOCK, 1995:72). Embora Ualalapi não lide com o "colonialismo industrial britânico moderno", descrito por McClintock, este romance de 
Khosa demonstra, de facto, a relevância do processo de abjecção relativo à expansão das fronteiras (e à ansiedade neurótica com respeito às fronteiras) como características definidoras da psicologia imperialista, da psicose, precisamente das fronteiras ou limites que não conseguem permanecer estáveis.

Na "Nota do Autor" em Ualalapi somos informados que o prazer da fronteira ambivalente de exclusão/inclusão assumiu um certo significado para o histórico Ngungunhane, na medida em que "um dos prazeres que cultivou em vida foi a incerteza dos limites reais das terras a seu mando" (KHOSA, 1990). Contudo, o lado contrário deste poder prazeroso sobre a expansão externa é também a sempre presente ameaça da diferença, a pressionar a partir de dentro.

A expansão do império masculino de Ngungunhane se depara, no auge do seu próprio crescimento, com a ameaça da volta ao feminino. Neste sentido, a barriga do imperador é descrita especificamente em expansão, pelo seu tamanho, invocando o inchaço antropófago, mas também uma gravidez monstruosa feminina. A barriga toma o aspecto de um falo grotescamente fora de contexto. Ele vai, literalmente, crescendo fisicamente, dia após dia, à medida que os desafios do império que ele absorve vão igualmente aumentando, consumindo metaforicamente os seus próprios vassalos. "Dizia isso com toda a pujança na voz, como se os milhares de vassalos coubessem no corpo bojudo que a todos ostentava e que medrava de dia para dia com as responsabilidades infinitas que o império lhe dava" (KHOSA, 1990:62).

Central na representação satírica de Khosa da devassidão imperial é, portanto, a ameaça do colapso absoluto da fronteira que constitui a diferença sexual. Assim, no auge da masculinidade extrema do império, pode-se distinguir o medo que o povo tem de um retorno ao feminino, de uma perda das fronteiras sexuais, expressas neste episódio através da imagem da excessiva menstruação feminina. Numa emulação irónica da expansão do império, o expelir de sangue por Damboia comporta-se como o império em si mesmo e ultrapassa toda e qualquer fronteira, na medida em que quebra as bilhas de barro e escorre para os rios. Domina literalmente o espaço físico, e reconfigura o mapeamento do território. Tal como observa Kristeva relativamente ao tabu da menstruação:

Menstrual blood [...] stands for the danger issuing from within the identity (social or sexual); it threatens the relationship between the sexes within a social 
aggregate and, through internalization, the identity of each sex in the face of sexual difference. (KRISTEVA, 1982:71)

Esta é, portanto, a razão de os homens serem representados como impotentes, inférteis, surdos e loucos ao entrarem em contacto com Damboia.

A necessidade de feminizar o inimigo masculino e ameaçador explica também a forma excessiva como o guerreiro Ualalapi matara anteriormente o seu inimigo Mafemane. Como aponta Jared Banks relativamente a este incidente, "the repeated plunging of the spear into [Mafemane's] body is disturbing in its excess. It is as if it is not sufficient to simply kill the opposition" (BANKS, 2010:187). Enquanto Banks brilhantemente reconhece aqui uma metáfora da reescrita da historiografia por Ualalapi, por meio de um "apagar" físico e literal de Mafemane, eliminando-o da História, tal incidente pode igualmente ser entendido como uma tentativa de Ualalapi de fazer do seu inimigo uma "mulher" - na medida em que o leva a sangrar excessiva e desnecessariamente -, além de ser essa uma forma de o eliminar da História.

Em verdade, não é surpresa que o corpo feminino que aflui e derrama em demasia se torne um significante para o discurso oral não-autorizado e não-oficial. O facto dos homens exauridos perderem o poder da audição e da coerência vê-se compensado pelo facto de as mulheres encontrarem o poder de contar relatos orais do acontecido, a versão alternativa que o narrador de Khosa vem apresentar. Também neste caso as palavras desenfreadas da mulher não podem ser impedidas, apesar dos esforços do Imperador que, tentando limitar o dano, viaja por toda a nação a contar a sua própria propaganda oficial, e positiva, fazendo lembrar o controlo de informação próprio do regime marxista-leninista. Nesta batalha pelas palavras e a sua autoridade na História, Banks expôs muito astutamente a etimologia do nome Ualalapi (que contem elementos em português das palavras 'uivo' e 'lápis') argumentando a favor de paralelismos que descrevem "the murder and violence of exclusionary narratives be they written or oral" (BANKS, 2010:190)5. A isto acrescentaria o facto de que Khosa apresenta a abjecção da matéria física, sexualmente incorporada, como a força estruturante destas exclusões sociais, linguísticas e históricas.

5. Para uma excelente leitura da cultura oral em Ualalapi, recomendo a consulta do artigo de Ana Mafalda Leite, "A Dimensão Anti-Épica da Moderna Ficção Moçambicana: Ualalapi de U. B. K Khosa" (AFOLABI, 2010, p. 219-30). 
As três histórias na colecção de Chiziane estão, por outro lado, ligadas precisamente pela sua recusa satírica em aceitar as forças de abjecção, sexualmente essencialistas, como a única forma de falar sobre o corpo feminino na e como nação. A psicologia do abjecto é central para o incidente que abre a narrativa do primeiro conto de Andorinhas: "Quem manda aqui?". Neste conto, a ênfase não recai sobre o fluxo menstrual feminino, mas antes no excremento. $\mathrm{O}$ imperador Ngungunhane acaba de comer uma refeição saciante quando uma andorinha voa sobre ele e defeca no seu olho. Tal como Kristeva observa, em contraste com o sangue menstrual que traz o perigo a partir de dentro: "excrement and its equivalents (decay, infection, disease, corpse, etc.) stand for the danger to identity that comes from without: the ego threatened by the nonego, society threatened by its outside, life by death" (KRISTEVA, 1982:71).

Uma vez mais, é a masculinidade do Imperador que é directamente enfraquecida pela incontinência da andorinha. Desta vez, porém, trata-se de uma ameaça constituída pelo "outro" masculino, no exterior, e não de um medo perante o feminino interior. O Imperador não hesita em culpabilizar os chopes, os seus inimigos mortais e machos, pelo ataque. Foi no momento em que pensava ser "o único macho na superfície da terra" quando "uma andorinha canta alegre no espaço. De pança também cheia, baila. Liberta os intestinos e a caganita balança na cloaca. Cede à gravidade e cai no olho do imperador" (CHIZIANE, 2008:15).

A resposta do imperador ao pássaro é paranóica. Ele convoca todos os seus generais e ordena que reúnam todas as pessoas e partam numa longa viagem para capturar todas as andorinhas no reino, e combater os chopes pelo caminho. Contudo, um dos seus generais, Nguyuza, sente-se inspirado para se rebelar, fazendo do pássaro defecador uma forma de "macho" idealizado. Ele pondera sobre o pássaro que levou a cabo a acção inicial e louva-o como um "bravo macho [que] ousou desafiar a virilidade do mais alto império" (CHIZIANE, 2008:20). Ele tem um sonho no qual conhece um espírito, que outrora tinha sido uma andorinha, e que lhe diz que um magnífico reino de andorinhas, Zulwine, o espera logo depois da linha do horizonte. A sacerdotisa, que mais tarde interpreta o seu sonho, também se transforma na andorinha encorajando-o a partir em busca dos seus próprios ideais, como homem livre, e não como súbdito do imperador.

Comandando o exército e suas famílias na inútil caça ao pássaro, o herói 
Nguyuzi acaba por chegar ao novo reino. Lá encontra novamente a sacerdotisa que o havia guiado, acabando por desertar do exército de Ngungunhane e libertar os seus seguidores, para nunca mais voltar para o decadente Império de Gaza. Neste sentido, acaba por cumprir o provérbio chope que diz "se queres conhecer a liberdade segue o rasto das andorinhas", que surge como epígrafe à colecção. Entretanto, com todo o exército ausente na missão de matar as andorinhas, os portugueses atacam e derrotam Ngungunhane, tomando-o como prisioneiro. Neste momento, uma andorinha defeca sobre ele uma vez mais, com a diferença de que desta vez o acidente é, curiosamente, fonte de renovados poderes, sendo que ele se rebela, ao cuspir na cara dos seus captores, que se sentem de tal forma assombrados pelas suas previsões de terror, que um deles se enforca e o outro foge e cede à loucura. Assim sendo, as andorinhas rebeldes são quem leva à derrota do imperador, mas são igualmente quem de novo o inspira a não aceitar a rendição passivamente. Tornam-se os agentes da sua vingança.

O excremento da andorinha, o perigo vindo de dentro, representado pelos chopes, marca agora precisamente essa fronteira ambígua, de dupla face, da abjecção, que constitui o próprio Ngungunhane como resistente, relativamente aos portugueses, eles mesmos, por sua vez "abjectados" por Ngungunhane, e condenados à mortalidade, loucura e morte. O Imperador vem, inclusive, a ser admirado pelos seus inimigos chopes, na medida em que "apesar das rivalidades, era um bom amigo" (CHIZIANE, 2008:42), em comparação com a opressão subsequente dos portugueses.

Ao narrar novamente a opressão dos chopes por Ngungunhane, e a rendição deste aos portugueses, segundo uma lenda de liberdade inteiramente chope, Chiziane reescreve eficazmente a genealogia do heroísmo Tsonga/ Nguni de Samora Machel numa nova versão, que contraria a masculinidade narcisista do imperador, apresentando uma terra dos sonhos, alternativa salvaguardada por Nguyuza. Nesta nova versão, o futuro herói da libertação de Moçambique será escolhido pelas andorinhas, destituindo eficazmente o nobremente derrotado Ngungunhane de Samora Machel, e predizendo a história de Eduardo Mondlane, narrada de forma diversa no segundo conto, "Maundlane, o Criador".

Este conto retoma as lendas da história familiar de Mondlane, em que ele teria sido eleito herói e recebido o nome de Chitlango, significando protec- 
tor, e Chivambo, em referência ao espírito do falecido rei que havia liderado o seu povo à vitória no passado. Chiziane narra como Mondlane havia sido inspirado pela sua mãe e avó a optar por uma educação colonial, de forma a suplantar os portugueses e assumir o manto heróico do seu falecido paí ${ }^{6}$. Após o falecimento da sua mãe e avó, as andorinhas inspiraram-no a cumprir as previsões de que ele seria "o homem da casa" (CHIZIANE, 2008:53) no sentido nacional, libertando o seu país, tal como fizera o rei Chivambo.

Depois de ter viajado pelo mundo, e estudado nos EUA, Mondlane retorna à sua oprimida terra-mãe e trabalha para unir as forças de resistência da FRELIMO sob um único líder, inspirado a voar como a águia. As pessoas admiram-no pela sua "magna estatura e musculatura delicada" (CHIZIANE, 2008:60), inferindo um tipo diferente de masculinidade que contrasta com o inchaço e decadência física de Ngungunhane. A sua morte, por via de um pacote bomba em Dar-es-Salaam, é eufemisticamente pouco enfatizada, sendo-lhe atribuído um lugar de menor destaque relativamente aos diálogos póstumos que ele teve com a sua inspiradora avó. Essa estratégia narrativa cumpre o propósito de minorar o impacto do muito discutido assassinato, que eventualmente faria de Samora Machel o líder da FRELIMO, ao mesmo tempo elevando Mondlane como se ele assumisse ainda o comando do seu povo, apesar de morto.

Segundo a sabedoria da versão de criação nacional, contada pela avó, Mondlane reúne os espíritos masculinos protectores de Chitlango e Chivambo, assim como os femininos de Dzovo e Mondlane, num equilíbrio sexuado entre o altruísmo maternal e os nomes masculinos que conotam martelos, pedras, escudos e armamento. Todos esses nomes afastam o nome pelo qual ele virá a ser conhecido na História, Eduardo, e que no conto de Chiziane é apenas usado no fim. Adicionalmente, o seu nome Mondlane, ou Maundlane, significa "criador, protector, encubador [...] piedoso, caridoso" (CHIZIANE, 2008:65), sendo que, na conduta de um híbrido masculino/feminino, o homem assume também o papel de mulher. Chiziane escreve "incubaste e pariste uma nação no teu ventre maundlane” (CHIZIANE, 2008:66). Neste senti-

6. Chiziane também recupera aqui o relato de A. D. Clerc e Chitlango Khambane em Chitlango. Filho de Chefe (NGOENHA, 1999:427). Ver também as memórias de Janet Mondlane das influências maternas em Eduardo Mondlane, London: Panaf Books 1972. "His mother Chude, after whom their eldest daughter was named, was a remarkable woman for she was a warrior who fought alongside her husband" (p. 132). 
do, a imagem do corpo masculino, imortal e grávido de Mondlane, incorpora a nação, com o feminino (tendo a avó como inspiração) a ser integrado no corpo nacional como uma necessidade, em vez de ser "abjectado" como uma ameaça, como no caso de Ngungunhane e Damboia. O mesmo será dizer que, quando a nação não é imperialista, a fronteira não vem a ser governada pelo narcisismo.

O atravessar das fronteiras sexuais absolutas, ao serviço da integração nacional, continua a ser desenvolvido no último conto da colecção "Mutola, a Ungida", que começa com a história famosa, e favorita do próprio Mondlane, de um pássaro num galinheiro, que acaba por ser uma águia e não uma gali$\mathrm{nha}^{7}$. Nesta história, a águia recupera, deste modo, o papel importante desempenhado pelas andorinhas nos primeiro e segundo contos como símbolos de liberdade e metáforas do Moçambique, então colonizado no galinheiro. Nesta história, ocorre não tanto um mapeamento da nação pelo corpo feminino, mas antes uma tentativa, sem êxito, de limitação da dimensão do corpo feminino por parte da nação. Apesar de ridicularizada como uma maria-rapaz e incentivada a desenvolver conhecimentos próprios de uma menina casadoura, Lourdes Mutola vem a tornar-se uma óptima atleta, chocando a nação quando joga futebol e marca golos pela equipa masculina. Os homens ficam literalmente estupefactos, na medida em que "não foi desenvolvido o vocabulário jornalístico para golos de mulher” (CHIZIANE, 2008:75).

Confrontada com esta ameaça à fronteira entre o "linguístico e o físico", a resposta dominante da nação é a negação da feminilidade do seu corpo por inteiro, insistindo que o seu talento a tornará masculina, e não permitindo que ela jogue com, ou contra, equipas masculinas, no caso de ela as derrotar e, consequentemente, assim as feminizar. Vindo a conquistar uma medalha de ouro olímpica em atletismo, Mutola torna-se, em última instância, a águia dourada, que suplanta os homens, que com ela jogavam na equipa masculina, ironicamente chamados "águias" na vida real, ainda que neste conto sejam descritos como galinhas. Neste sentido de transgressão, e recusa do

\footnotetext{
7. Este faz referência a uma parábola famosa que, segundo Chiziane, foi contada por Eduardo Mondlane na Igreja Presbiteriana em Chamanculo nos anos 60. Narra a história exemplar de uma águia (alegoricamente em representação do povo colonizado de Moçambique) que não estava disposta a permanecer confinada ao galinheiro colonialista, construída por convenção como uma "galinha", mas que escolheu abrir as suas asas e voar.
} 
essencialismo sexual, ela torna-se precisamente o emblema de uma nova e não-maternal nação moçambicana. Carregando a bandeira moçambicana, ela assume-se como a herdeira do legado das andorinhas, e das águias, das profecias do criador Eduardo Mondlane, da linhagem nacional alternativa a Ngungunhane, apresentada aqui como uma linhagem verdadeira e duradoura.

Se Mondlane equilibra a sua artilharia masculina com as capacidades de criação e educação, historicamente atribuídas à mulher, Mutola, uma mulher, igualmente abençoada pelos deuses, goza os poderes convencionalmente masculinos de um guerreiro, sendo neste aparente (e contra-histórico) cruzamento de géneros que Chiziane parece imaginar um novo casal fundador da nação. A autoridade conferida pelo êxito desta representação desportiva nacional é produtivamente redireccionada para a redefinição do corpo feminino, em termos que não dependam de binómios sexuais, de reprodutividade ou da abjecção sexual ou social da Mãe. Como pináculo desta outra genealogia moçambicana de inspiração chope, Mutola incorpora a nação, não como o Outro maternal imaginado, ou como o seu lado negro no expelir da Damboia, abjectamente menstruada, mas antes como o agente do seu próprio destino sexual e político, para lá da paranóia e do narcisismo da formação nacional do sujeito, fundada por um imaginário masculino, socialmente dominante.

A mitologia chope das andorinhas, amalgamada na parábola das águias de Mondlane, e a sua influência feminina genealógica, juntamente com a deslocação do Moçambique nguni de Samora Machel como uma força de abjecção, possibilita um campo discursivo, através do qual Chiziane consegue reinventar Moçambique como um ícone feminino para as mulheres. Ao se tornar uma águia, Mutola torna-se, pela lógica do conto famoso e anticolonial de Mondlane, a imagem de um Moçambique livre, prefigurado numa mulher, que superou o sexismo em vez de a ele sucumbir, e que poderá representar a nacionalidade precisamente porque ela transgrediu, em vez de reforçar, as fronteiras sexuais. Adicionalmente, uma nação pós-colonial "liberta" tem agora de voltar atrás, e libertar as suas mulheres através do relato das suas próprias mitologias de libertação, marcadas pelo género, de forma a estar verdadeiramente liberta, dentro das suas próprias fronteiras. 


\section{Referências Bibliográficas}

BANKS, Jared. "Violence and the (Re)Writing of History: A Reading of Ualalapi". In AFOLABI, Niyi (ed.). Emerging Perspectives on Ungulani Ba Ka Khosa. Prophet, Trickster and Provocateur. Trenton, N. J. : Africa World Press, 2010:173-191.

CAHEN, Michel. Nationalism and ethnicities. Lessons from Mozambique. In cphrc, 1999.

CHIZIANE, Paulina. As Andorinhas. Maputo: Índico, 2008.

CHIZIANE, Paulina. Eu Mulher em Mocambique. In AFONSO, Ana Elisa de Santana Afonso. Maputo: CNUM and AEMO, 1994.

CLERC, A. D. and KHAMBANE, Chitlango. Chitlango, filho de chefe. Maputo: Cadernos Tempo, 1990.

KHOSA,Ungulani Ba Ka. Ualalapi. Lisboa: Caminho, 1990 [1987].

KRISTEVA, Julia. Powers of Horror. An Essay on Abjection. Trans. Leon S. Roudiez. New York: Columbia University Press, 1982.

LEITE, Ana Mafalda. "A Dimensão Anti-Épica da Moderna Ficção Moçambicana: Ualalapi de U. B. K. Khosa”. In AFOLABI, Niyi (ed.). Emerging Perspectives on Ungulani Ba Ka Khosa. Prophet, Trickster and Provocateur. Trenton, N. J.: Africa World Press, 2010:219-230.

McCLINTOCK, Anne. Imperial Leather. Race, Gender and Sexuality in the Colonial Contest. New York and London: Routledge, 1995.

Eduardo Mondlane. London: Panaf Books, 1972.

NGOENHA, Severino Elias. "Os missionaries suícos face ao nacionalismo moçambicano. Entre a tsonganidade e a moçambicanidade”. In Lusotopie: 425-36. ago. 1999.

Recebido em 02 de Abril e aprovado em 08 de maio de 2010. 